\title{
¿Deberían interesarse los sociólogos por el marxismo analítico?
}

\author{
F.J. Miguel Quesada \\ Universitat Autònoma de Barcelona. Departament de Sociologia \\ 08193 Bellaterra (Barcelona). Spain
}

\section{Resumen}

El escrito presenta una visión crítica del marxismo analfitco, de sus bases metodológicas y de sus consecuencias no deseadas.

Palabras clave: marxismo, individualismo, acción colectiva.

Abastract. The interest of the sociologists for the analitic marxism

The text shows a critical review on analytical marxism, her methodological basis and nonwanted consequences.

Key words: marxism, individualism, colective action

\section{Sumario}

1. Metodología: individualismo, mecanismos y explicación

3. Consectuencias no deseadas y acción colectiva

2. Modelo de conducta individual: el tacionalismo metodológico

Bibliografía

La recepción del marxismo analítico por parte de la sociologia ha presentado, desde el principio, recelos y cautelas múltiples, dando lugar, con el paso del tiempo, a una relación incómoda que podría resumirse como sigue: los representantes del marxismo analítico reclamaban trabajo sociológico para nutrir su teoría, y entretanto la sociología reclamaba un marco teórico acabado y consistente para fundamentar sus análisis. Mientras tanto, Elster ha escrito manuales de introducción a la sociología ${ }^{1}$, Wright y Przeworski trabajan en un proyecto internacional de estudio de estructura social, Taylor ha desarrollado una "teo- 
ría de las revoluciones" de carácter claramente sociológico, etc. ¿Qué sentido tiene hoy día para un sociólogo el interesarse por el matxismo analítico?

A continuación se expone parte de un catálogo básico de ámbitos plenamente sociologicos que incluyen producción por parte del marxismo analítico, o bien presentan posibilidades de aplicación. El catálogo completo está ordenado siguiendo un criterio lógico y comienza con dos cuestiones de base (la metodología y el modelo de conducta humana), para pasar después al tema de los resultados de la agregación de acciones sociales (la acción colectiva y la formación social de preferencias), concluyendo con la configuración de la estructura social ${ }^{2}$. Es preciso advertir que, en general, el marxismo analítico tiene una tendencia clara de avanzar en sus explicaciones del nivel "micro" hacia el nivel «macro", por lo que es importante considerar detalladamente tanto su metodología como su modelo de conducta humana, objeto del presente resumen.

\section{Metodología: individualismo, mecanismos y explicación}

Desde la perspectiva metodológica, el punto claramente diferencial del marxismo analítico respecto a otras escuelas marxistas es el abandono de la "dialéctican. Revisando la historia de este rechazo puede descubrirse cómo su argumentación fluye a través de tres líneas diferentes: respecto a la unidad analitica mínima, la defensa del individualismo frente al colectivismo, o la acción estratégica como "átomo explicativo" de la realidad social; respecto al formato explicativo, la defensa de los mecanismos frente a los enunciados legaliformes; y respecto a las hipótesis o conjeturas fundamentales que funcionan como mecanismos de inteligibilidad de la explicación, la defensa de la intencionalidad, o el momento ineludiblemente hermenéutico de la explicación en ciencias sociales ${ }^{3}$.

El marxismo analítico desplaza el peso de la explicación del colectivo al individuo, así como de las leyes generales a los mecanismos explicativos. Esto pretende ser un acto de refinamiento epistemológico coherente con las nuevas tendencias de la filosofia analítica. En este contexto, el marxismo analítico ha dado muestras de una actitud "realista" relacionando su propuesta ante todo con las llamadas condiciones de aceptabilidad de los enunciados por parte de la comunidad científica. De este modo queda claro que el marxismo analítico tiene una concepción al menos tan sociológica como filosófica de la ciencia y la metodología. Según el marxismo analítico, la "aceptabilidad" científica de una explicación está vinculada explícitamente a las condiciones formales de la explicación. A diferencia de las condiciones materiales de la explicación, que aluden a la verdad o falsedad de la misma, las condiciones formales hacen referencia a la "corrección", o "propiedad" establecida por una cierta comunidad

2. Este artículo forma parre de un trabajo más amplio.

3. En este último punto hay que mencionar expresamente la postura contraria de Cohen y de Van Parijs, al aceptar el modelo de explicación funcional o teleológica (Cohen, 1978, 1982). 
científica. Van Parijs señala dos condiciones formales de la explicación, a saber, el vínculo causal y el mecanismo de inteligibilidad (Van Parijs, 1981). Una regularidad detectada apunta hacia el vinculo causal, que hace referencia a conjuntos de condiciones de necesidad y suficiencia para producir el fenómeno en cuestión. Por su parte, los mecanismos son requeridos como marcos de inteligibilidad que han de ser reconocidos por la comunidad científica.

Este modelo epistemológico permite conjeturar diferentes mecanismos de inteligibilidad fundamentales para diferentes ámbitos cientificos. Ordenadas de mayor a menor en función de la información disponible para establecer las condiciones explicativas y deductivas, tenemos tres ejemplos de conjeturas (Elster, 1983a): la hipótesis de invarianza en la explicación causal de las fisicas teóricas, la hipótesis de selección natural en la explicación funcional de la biologia, y la hipótesis de comportamiento racional en la explicación intencional de las ciencias sociales.

No todos los representantes del marxismo analítico suscriben tan tajante diferenciación. Sobre todo Elster acepta los formatos causal e intencional en las ciencias sociales, pero excluye el formato funcional. En la discusión metodológica sobre el formato de la explicación ${ }^{4}$, pueden encontrarse las claves para la exclusión de la dialéctica como "método" y para la configuración de una estrategia explícita de explicación común a las ciencias sociales. Lo que no gusta a Elster ${ }^{5}$ de la propuesta "dialéctica" es que no son las propiedades de las macroentidades sometidas a leyes teleológicas las que permiten explicar los fenómenos sociales, como tampoco lo son las propiedades de los individuos considerados aisladamente, sino la lógica que genera la interacción entre individuos desigualmente dotados (de recursos, de preferencias y de información). Esta concepción de explicación recoje un pretendido sentido weberiano, y se muestra estrechamente ligada a la concepción de individuo y a la idea de racionalidad.

Hay varias alternativas a lo que el marxismo analítico llama marxismo funcionalista (Elster, 1982); por ejempio, si se consideran, desde una perspectiva "intencionalista", fenómenos que impliquen situaciones conflictuales de interacción estratégica, puede ser útil la formulación de explicaciones en términos de teoria de juegos. Por el contrario, si se consideran comportamientos como la interaccion entre agentes paramétricamente racionales o la formación de las preferencias, las explicaciones marxistas son de tipo causal y no funcional ${ }^{6}$.

4. Una buena parte de la discusión ha sido publicada en España en la revista Zona Abierta. Puede encontrarse la posición de Elster, 1982, I986b, Cohen, 1982, Van Parijs, 1982, Przeworski, I985, Roemer, 1985b, Wood, 1986, Levine, Sober y Wright, 1987.

5. Elster, 1978, cap. 5; 1979, caps. 1 y 2; 1983b, apéndice 1 .

6. Van Parijs aplica explicaciones de tipo uevolucionarion como alternativa a las explicaciones funcionalistas. Desde posiciones alejadas del marxismo analítico, a estas explicaciones Fararo las llama "principio conductista de la racionalidad adaptativa" (Fararo, 1989) y Homans, simplemente, "conductismo" (Homans, 1961). Una explicación evolucionaria (EE) presupone un mecanismo de filtro a partir de las consecuencias efectivas de una accion. Existen dos 


\section{Modelo de conducta individual: el racionalismo metodológico}

En términos genéricos, el modelo explicativo del marxismo analítico se sustenta en los supuestos de la teoría matemática de los juegos de estrategia y configura un determinado "modelo de conducta individual". Este modelo se define explícitamente en contraste con el llamado enfoque económico de la conducta racional bumana, que aplica el análisis económico estándar a distintas realidades sociológicas ${ }^{7}$.

El problema es, precisamente, el concepto de racionalidad utilizado, o mejor planteado: los límites de la hipótesis de racionalidad que fundamenta las teorías de la acción (Jordana, 1991). El marxismo analítico supera el problema de la economía neoclásica que aqueja a los economistas desde principios de los afios cincuenta al adoptar un modelo de conducta no comprometido con la hipótesis dura de la racionalidad optimizadora. Existen diversas hipótesis o conjeturas potencialmente utilizables como componentes de la explicación de la conducta en ciencias sociales. Van desde la aceptación de un mecanismo de inteligibilidad mínimo hasta el racionalismo típico de la economía neoclásica y pueden ordenarse de menor a mayor dureza en sus requerimientos. A todas ellas es común la consideración de que toda explicación científica en ciencias sociales asume la intervención de algún tipo de mecanismo (condición general de inteligibilidad). Sin embargo, pueden asumirse diversas ampliaciones:

1. Algún tipo de mecanismo que opera a través del individuo (la hipótesis del comportamiento que caracteriza a todo individualismo metodológico).

2. Algún tipo de mecanismo psicologico que opera a través del individuo (posición calificable, en general, como psicologismo metodológico).

3. Algún tipo de mecanismo psicologico que opera a través de las intenciones del individuo (intencionalismo metodológico).

4. Algún tipo de mecanismo psicológico de generación de la acción que opera a través de las intenciones del individuo (accionalismo metodológico), en tal caso todo fenómeno social puede ser explicado directamente a partir de las acciones (racionales o no), o bien a partir de los efectos agregados de las mismas 8 .

5. Algún tipo de mecanismo psicológico de generación de la acción que opera a través de las intenciones del individuo, y que en riltima instancia consiste en decisiones racionales en un sentido amplio (racionalismo metodológico).

6. Algún tipo de mecanismo psicológico de generación de la acción que opera

subtipos: las $\mathrm{EE}$ de selección natural y las $\mathrm{EE}$ de refuerzo. Las primeras operan a través de un mecarismo de selección de características por selección de los individuos que son portadores. Las últimas operan a través de un mecanismo de selección de características en el interior del individuo (Van Patijs, 1981).

7. Para hacerse una idea cabal de esta perspectiva, se puede consultar (con precaución) McKenzie y Tutlock, 1980, o Becker, 1973-4, 1976.

8. Como interaccionismo metodológico, Boudon le presta la máxima atención (Boudon, 1979), mientras que Van Parijs declara su insuficiencia como modelo explicativo en ciencias sociales sin explicar el porqué (Van Parijs, 1990, p. 41). 
a través de las intenciones del individuo, y que en última instancia consiste en decisiones racionales en un sentido restringido ${ }^{9}$ (economicismo metodológico).

El tipo de racionalidad restringida exigida por los modelos de la economía neoclásica implica la concurrencia de seis condiciones, lógicamente independientes entre sí, a saber:

1. Racionalidad egoista, referida siempre a la utilidad del propio individuo.

2. Otientada a intereses estrictamente materiales.

3. Maximizadora de la urilidad.

4. Arquimediana, es decir, se asume que los diferentes factores intervinientes en la composición de la función de utilidad son intercambiables, por lo que se puede establecer un patrón monetario para expresar esta utilidad ${ }^{10}$.

5. Objetiva, con información perfecta del ambiente.

6. Paramétrica, con características dadas del ambiente, es decir, estados del mundo con probabilidad fija, bien sea $\mathrm{p}=1$ (ambiente determinista, o de certidumbre), bien sea $\mathrm{p}>1$ (ambiente estocástico, o de tiesgo).

Tomando como referente los "manuales de sociologfa" de Elster (Elster, 1989a, 1989b) y el modelo epistemológico de Van Parijs (Van Parijs, 198I, 1990), el marxismo analítico tendría actualmente un compromiso con el «racionalismo metodológicon, y no con la hipótesis de racionalidad económica en sentido restringido. La racionalidad asumida, en general, por el marxismo analítico es de tipo no estrictamente egoísta, orientada por diversos subconjuntos de intereses, satisfactora antes que maximizadora, difícilmente teducible a un patrón monetario, subjetiva en términos de información imperfecta, y estratégica, es decir, se desarrolla en un ambiente de interacción con otros agentes racionales. En realidad los mecanismos explicativos buscados por el marxismo analítico tienen menos que ver con las intenciones de los individuos que con los resultados de las acciones generadas por tales intenciones, $y$, al igual que en Pareto, tales intenciones no necesariamente deben ser conscientes al individuo, ni necesariamente están guiadas por un cálculo finalista, lo que abre la posibilidad a la consideración de normas sociaies internalizadas que no hacen referencia a racionalidad alguna, así como a otros mecanismos explorados por el marxismo analítico (compromiso previo, debilidad de la voluntad, recompensas diferidas, preferencias de segundo orden, ordenaciones lexicográficas de preferencias, entre otros).

9. Es interesante hacer notar cómo diferentes desarrollos de la teoria económica de la segunda mitad del presente siglo han violado algunas de estas condiciones; especialmente el concepto de "racionalidad satisfactora" (Simon, 1982) y las aplicaciones de la teoría matemática de los juegos de estracegia (Neumann y Morgnestern, 1944).

10. El término proviene de Borch (Borch, 1968) y hace referencia al principio básico de la hidrostática o equivalencia entre el volumen del fluido desalojado por un cuerpo en inmersión y el volumen del cuerpo en cuestión. 


\section{Consecuencias no deseadas y acción colectiva}

Acabamos de afirmar que el punto de mira de la explicación del marxismo analítico se sitúa sobre las consecuencias de la acción intencional. Sin entrar en mayor detalle, el marxismo analítico acepta que toda acción genera efectos materiales sobre el mundo social y, simultáneamente, cambios en las dotaciones "mentales" de los individuos. El problema de las consecuencias materiales de la acción social, cuestión esencialmente sociológica, se inscribe en este ámbito, así como las paradojas de las consecuencias no-deseadas y el problema de la acción colectiva. Esta idea, por otro lado, no es enteramente ajena a Marx, quien hace referencia a mecanismos de agregación de resultados, como el de la "mano invisible" del mercado. Esta simple idea puede formalizarse sin excesivas complicaciones utilizando la teoría matemática de los juegos de estrategia, haciéndola aún más atractiva al marxismo analítico. Otros autores no-marxistas, a lo largo de los años setenta, han tratado las mismas ideas. En este sentido, buena parte del trabajo de Elster desde 1978 -que se sintetiza en Elster, 1985bpuede entenderse como un diálogo constante con Boudon, Hirschman, Olson, o Schelling ${ }^{11}$, autores dedicados a la sustentación de esta perspectiva.

El interés para la sociología de este tema es considerable, dada la importancia de estos contextos sociales en los que se enfrentan los intereses individuales contra la acción común. La paradoja esencial de la acción colectiva puede resumirse en que este tipo de acción suele presentarse como individualmente irracional. El marxismo analítico propone la tutilización de la teoría de los juegos de estrategia para desentrañar la lógica de la situación de la acción cooperativa, de forma que se evidencie cómo los intereses de los individuos influyen en la decisión de cooperar estratégicamente.

Hay aún, al menos, otros dos aspectos del problema que podrían tener interés sociológico. El primero es lo que Eister denomina la udebilidad de voluntad", en referencia a la consideración del modelo de "acción colectiva" en el interior de una persona, de forma que un individuo tenga preferencia por recompensas inmediatas pequeñas sobre recompensas mayores diferidas. Tomando a cada persona como una sucesión de individuos momentáneos, se puede entender que una acción actual tendrá que guiarse por un contexto estratégico en que se incluyan otros "yo", señaladamente los posteriores. De esta forma se pueden modelizar interesantes procesos que tienen relación con el consumo -en especial casos como el tabaco y otras drogas-... Por otro lado, una extensión de esta última visión a las decisiones políticas, puede aportar una forma nueva de entender los modelos de crecimiento sostenible y el sentido general del ecologismo, como problema de acción colectiva temporal ${ }^{12}$,

11. Las referencias esenciales de estos autores no-marxistas pueden encontrarse en Boudon, 1977; Hirschman, 1970; Olson, 1971; Schelling, 1978.

12. Una cuesción relevante en esta línea sería: $q$ Qué mecanismos gobiernan las decisiones actuales de colaborar con un habitante de este planeta dentro de cincuenta afios? Puede parecer desencaminado, pero ifumina una vía de estudio sobre aspectos como el reciclaje de residuos, o las actizudes frente a las nuevas energías. 
Cuadro 1 .

\begin{tabular}{lll}
\hline & Beneficios egoístas & Beneficios no egoistas \\
\hline Orientados a la acción & Activismo & Altruismo/moralidad \\
\hline Orientados al resultado & Racionalidad restringida & Normas sociales \\
\hline
\end{tabular}

es decir, acción colectiva entre actores actuales y las generaciones venideras.

Para abrir una vfa de análisis de la acción colectiva, el marxismo analítico debe alejarse del modelo de racionalidad restringida. La ruptura puede efectuarse sobre varias de las condiciones vistas anteriormente. Elster afronta la cuestión proponiendo un análisis conceptual de la utilidad, estableciendo diferentes categorías de "beneficios" (Elster, 1985b, p. 54-5). Así, existen dos dimensiones, correspondientes a: a) a los beneficios egoístas frente a los noegoístas, y 6 ) a los beneficios orientados al resultado frente a los orientados al proceso de la acción (cuadro 1). Estas dos distinciones generan una cuatrilogía clasificatoria de motivaciones para la acción. Si se acepta la subclase de motivaciones egoístas orientadas al resultado como la única relevante para la explicación, los actores racionales, egoístas y orientados a los resultados jamás elegirfan cooperar ${ }^{13}$. Ésta es la perspectiva del anteriormente llamado ueconomísmo metodológicon. Pero como la acción colectiva existe, resulta necesario explorar los otros tres subconjuntos de motivaciones.

En primer lugar, es posible que los motivos egoístas para la acción se orienten hacia el proceso mismo de la acción, y no hacia el resultado. Esta perspectiva nos podría ayudar a plantear — sociológicamente y desde el marxismo analítico- problemas como el del trabajo del voluntariado social, aunque Elster critica este cambio, pues el hecho de ser la acción fuente de satisfacción no implica que sea fuente de motivación ${ }^{14}$. Más aún, el activismo motivado por la satisfacción por la misma acción puede convertirse en una estrategia no cooperativa si se cambia la escala temporal, es decir, un movimiento social puede fracasar ante la defección de aquéllos que se desmotivan por "falta de acción", dado que la acción política puede requerir en ocasiones estrategias de retardo táctico, o de "un paso atrás y dos adelante», inaceptables para los egoístas orientados a la acción.

En segundo lugar, es posible que los motivos sean no-egoístas y se orienten hacia el resultado. Dentro de esta categoría se incluye tanto el altruismo personal $^{15}$, como la moralidad o cualquier clase de evaluación impersonal, del tipo de las normas kantianas. Este caso está muy generalizado en la realidad social, y Elster advierte en este punto que los modelos explicativos deben con-

13. Es la solución del dilema del prisionero.

14. Elster lo explica como un caso de "estados que son esencialmente subproductos". Ver Elster, $1983 \mathrm{~b}$, cap. II.

15. Es decir, ni ayudo a todo el mundo, ni ayudo a codos los que ayudo por un igual. 
templar el hecho de la desigualdad en los orígenes de las motivaciones de los implicados en una acción colectiva: "En el caso normal, la población contará con individuos que varíen en su grado de altruismo, así como con algunos sujetos egoístas, algunos sujetos morales, etcétera" (Elster, 1985b, p. 63).

Este esquema, como puede verse, se aleja totalmente de la corriente de interpretación económica de la conducta, pero aún se hace más explícitamente sociológico con la consideración del cuarto grupo de motivaciones: las noegoístas orientadas al proceso, tradicionalmente conocidas como "normas sociales». Su incumplimiento genera vergüenza y desartaigo, pero jamás culpa como sucede con las normas morales. Las normas sociales no son tratadas como filtros exógenos a la decisión, sino como auténticas preferencias y motivos para la acción, por ello los últimos desarrollos del marxismo analítico en términos de esquemas teóricos explicativos de la acción colectiva se encaminan a esclarecer el lugar de las normas sociales dentro de los procesos de elección, dada la relevancia de las mismas para los efectos de la acción.

\section{Bibliografía}

BECKER, Gary S. (1973). «A Theory of Marriage: Part I". Journal of Politic Economy, vol. 81, julio/agosto, p. 813-846.

-(1974). "A Theory of Marriage: Part II". Journal of Politic Economy, vol. 82, marzo/abril, p. S11-\$26.

-(1976). The Economic Approach to Human Behavior. Chicago: University of Chicago Press.

-(1977). Efectos perversos y Orden social. México: Premia Editora, 1980.

-(1979). La logica de lo social. Una introducción al análisis sociologico. Madrid: Rialp, 1981.

BoRCH, K. (1968). The Economics of Incertainty. Princetown, N.J.: Princetown University Press.

COHEN, G.A. (1978). La teoria de la historia de Karl Marx: una defensa. Madrid: Siglo XXI Editores, 1983.

-(1982). "Réplica a "Marxismo, funcionalismo y teoría de juegos" de Elster". Zona Abierta, 33 (1984), 64-80.

ELSTER, J. (1979). Ulysses and the Sirens: Srudies in rationality and irrationality. Cambridge: Cambridge University Press, ed. rev. 1984.

- (1982). "Marxismo, funcionalismo y teoria de juegos. Alegato en favor del individualismo metodológicon. Zona Abierta, 33 (1984), 21-62.

-(1983a). El Cambio Tecnologico. Investigaciones sobre la racionalidad y la transformación social. Barcelona: Gedisa, 1990.

—(1983b). Uvas amargas: Sobre la subversion de la racionalidad. Barcelona: Península (Ideas; 4), 1988.

-(1985b). «Racionalidad, moralidad y acción colectiva». Zona Abierta, 54/55 (1990), p. 43-68.

-(1986b). "Nuevas reflexiones sobre marxismo, funcionalismo y teoría de juegos". Zona Abierta, 43-44 (1987), p. 25-52.

-(1989a). El Cemento de la Sociedad: Las paradojas del orden social Barcelona: Gedisa, 1991. 
-(1989b). Tuercas y tornillos: Introducción a las ciencias sociales. Barcelona: Gedisa, 1990.

FARARO, Th.J. (1989). The meaning of general theoretical sociology. Cambridge: Cambridge Universicy Press.

HIRSCHMAN, Albert (1970). Salida, voz y lealtad México: Fondo de Cultura Económica, 1977.

HomaNs, George C. (1961). Social Behaviour: Its Elementary Forms. Nueva York: Harcourt, Brace, 1974.

JORDANA, Jacint (1991). El limits de la hipòtesi de racionalitat com a fonament per a les teories de l'accib. Tesis doctoral. Departamento de Sociología y Metodología de las ciencias sociales. Universidad de Barcelona.

LEVINE; SOBER; WRIGHT (1987). "Marxismo e individuałtsmo metodológicon. Zona Abierta, 41-42, p. 131-157.

MCKeNZIE y TULLOCK (1980). La nueva frontera de la economia. Madrid: EspasaCaipe.

Olson, Mancur (1971). The Logic of Colective Actions. Cambridge, Mass.: Harvard University Press, 1982.

PRZEWORSKI, Adam (1985). «Marxismo y elección racional». Zona Abierta, 45 (1987), p. 97-136.

ROEMER, (1985b). "Marxismo de "elección racional": algunas consideraciones de método y contenidon. En ROEMER (comp.) (1986). El marxismo: Una perspectiva analttica. México: Fondo de Cutura Económica, 1989. También en Zona Abierta, 45 (1987), p. 137-152.

SCHELING, Thomas (1978). Micromotives and Macrobehavior. Nueva York: Norton $\& \mathrm{Co}$.

SimoN, H. (1982). Models of Bounded Rationality: Behavioral Economics and Business Organizations, vol. II. Cambridge, Mass.: The MIT Press.

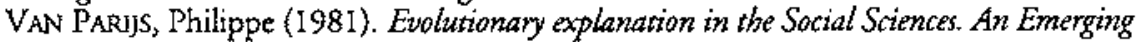
Paradigm. Londres: Tavistock.

-(1982). «El funcionalismo marxista rehabilitado.Comentario sobre Elster». Zona Abierta, 33 (1984), 81-101.

-(1990). Le modele économique et ses rivaux. Introduction à la practique de l'épistémologie des sciences sociales. Ginebra-París: Libreria Dtoz.

VON NEUMAN, J.; MoRgenstern, O. (1944). The Theory of Games and Economic Behavior. Princetown: Princetown University Press, 1953.

WOOD, Allen W. (1986). «Materialismo histórico y explicación funcional». Zona Abierta, $43-44$ (1987), p. 1-24. 